\title{
Functional role of biofouling linked to aquaculture facilities in Mediterranean enclosed locations
}

\author{
Valeria Montalto ${ }^{1, *}$, Alessandro Rinaldi ${ }^{1}$, Francesca Ape ${ }^{1}$, M. Cristina Mangano ${ }^{2,3}$, \\ Michele Gristina ${ }^{1}$, Gianluca Sarà ${ }^{3}$, Simone Mirto ${ }^{1}$ \\ ${ }^{1}$ Institute for the Study of Anthropogenic Impacts and Sustainability in Marine Environment (IAS - CNR), \\ Via G. da Verrazzano, 17, 91014 Castellammare del Golfo, TP, Italy \\ ${ }^{2}$ Stazione Zoologica Anton Dohrn, Dipartimento Ecologia Marina Integrata, Sede Interdipartimentale della Sicilia, \\ Lungomare Cristoforo Colombo (complesso Roosevelt), 90142 Palermo, Italy \\ ${ }^{3}$ Dipartimento di Scienze della Terra e del Mare, University of Palermo, Viale delle Scienze Ed. 16, 90128 Palermo, Italy
}

\begin{abstract}
Biofouling is generally considered a serious threat for human coastal activities such as aquaculture, and the ecological role of fouling organisms associated with fish-farm cages remains one of the most debated topics in the ecological field. However, although biofouling may cause significant problems related to human health, environmental impact and financial losses, in the past decade there has been an increasing interest in developing methods to promote the growth of biofouling on artificial structures as a strategy to mitigate human impacts and reduce the organic enrichment caused by net-cage fish farming. Here we investigated the filtration activity of biofouling assemblages colonizing artificial substrata located within a harbor. The main objective of the study was to determine if and how changes in composition and functioning of biofouling may be affected by hypoxic conditions that periodically occur within the port site selected for this study. To this purpose, artificial panels were used as biofouling collectors and were brought back to the laboratory seasonally where they were divided in 3 subgroups and acclimated at 3 different oxygen levels to mimic the naturally occurring oxygenic conditions. Clearance and respiration rates of each community were measured 6 and $24 \mathrm{~h}$ after the beginning of each treatment. Regardless of experimental conditions, performance of the communities was affected by the seasonality and the amount of biomass recruiting on the panels, mainly composed of crustaceans, ascidians, polychaetes, seaweeds and several introduced species. Our study demonstrated that, in particular cases, fouling assemblages linked to aquaculture facilities may contribute to reducing environmental impact and at the same time may serve as input for their re-use in different disciplines.
\end{abstract}

KEY WORDS: Bioremediation $\cdot$ Coastal aquaculture $\cdot$ Fouling $\cdot$ Hypoxia

\section{INTRODUCTION}

A major constraint in Mediterranean aquaculture is the access to coastal space and, although offshore aquaculture may offer a solution, in several countries aquaculture is still most common at sheltered sites, such as lagoons or semi-enclosed bays. These sites bring large advantages by being close to coastal infrastructures, but the likelihood to generate detrimental local ecological effects with severe repercussions on habitat quality is high. Water column and sediment quality and benthic biota can be im-

\footnotetext{
${ }^{*}$ Corresponding author: valeria.montalto@ias.cnr.it
}

paired at a local scale (i.e. beneath the cages and in the surroundings; Price et al. 2015, Gentry et al. 2017) due to depletion of dissolved oxygen (DO) and nutrient enrichment (Neofitou et al. 2010). Additionally, aquaculture facilities and other artificial structures work as attachment substrata facilitating the establishment and the spread of fouling communities, i.e. the undesirable accumulation of different organisms on wetted artificial structures, which, in turn, could impair shipping industry and industrial aquatic operations such as aquaculture (Sarà et al. 2007).

() The authors 2020. Open Access under Creative Commons by Attribution Licence. Use, distribution and reproduction are unrestricted. Authors and original publication must be credited. 
Generally, biofouling consists of multi-specific assemblages of microorganisms, algae and animals belonging to different trophic levels which may fulfill several ecological functions. Biofouling is prevalent in marine environments, causing significant problems related to health risks, environmental impact and financial losses (e.g. Wang et al. 2017). Detrimental effects are highly variable and depend on the extent, type and ecological roles of biofouling which are linked to many factors such as the biological traits of the species comprising the assemblage, aquaculture rearing techniques (subtidal, intertidal or suspended longlines), geographic location and local hydrodynamics (e.g Rivero et al. 2013). The presence of biofouling may change the hydrodynamic regimes affecting the ecological functioning of surrounding ecosystems (Mazouni et al. 2001, Wahl 2008) by altering the interactions within local assemblages (e.g. directly competing for resources with cultured organisms) and generating extra-economic costs. The direct economic cost of controlling biofouling in aquaculture is estimated conservatively at around $5-10 \%$ of the industry value (Fitridge et al. 2012), and is mainly related to the increased maintenance of overloaded infrastructure and production loss due to low growth and/or poorer quality of farmed species (Lane \& Willemsen 2004).

Recent research has, however, emphasized the role of biofouling as an environmental mitigator of local detrimental impacts in that it is able to reduce the organic enrichment generated by fish farming at micro- and mesoscales, particularly where the aquaculture sites are within enclosed locations (Hughes et al. 2005, Floerl et al. 2016).

Indeed, the most common and abundant taxa among fouling organisms are usually suspension feeders and detritivorous (Mangano et al. 2019) and which thus may be able to exert a strong 'cleaning' (Sarà \& Mazzola 2004) effect due to their effective pumping performance.

Thus, the debate on the functional role of biofouling is still unresolved, and there is an urgent need to increase our understanding of the potential positive role of biofouling in reducing local detrimental impact caused by aquaculture in enclosed locations. Reassessing the role of fouling in more positive terms may bring scientists to re-think management measures in enclosed habitats and to inform stakeholders about other options in managing biofouling in aquaculture. While it is crucial to gather data on if and how the ability of biofouling to retain fish-derived organic matter is spatially and temporally constant and persistent over time, in order to design effective management measures, it is necessary to understand whether local hypoxia events (highly frequent under enclosed shallow conditions; e.g. Bravo \& Montañes 2001) can impair the rate of pumping in biofouling communities. Hypoxia can reduce the filtration efficiency of suspension feeders, diminishing their ability to retain organic particles (e.g. Sebens et al. 2016, Tang \& Riisgård 2018); in the case of aquaculture, fish feces and uneaten food.

Here we present a study designed to (1) investigate the filtration activity of fouling assemblages colonizing artificial substrata mounted on finfish cages located in shallow enclosed waters within a Mediterranean harbour and (2) study how changes in the composition, and thus in the functioning of biofouling - as expressed by the filtration potential - may be affected by suboptimal environmental conditions (i.e. levels of DO in a range where physiological performances may be reduced without causing the death of aquatic organisms) that periodically occur within coastal shallow sites such as those chosen in this study.

\section{MATERIALS AND METHODS}

\subsection{Study area, experimental design and sampling}

The study was performed in a system of aquaculture fish cages (Ittica San Giorgio s.r.1.) located in southern Sicily (Licata harbour, $37.087^{\circ} \mathrm{N}, 13.943^{\circ} \mathrm{E}$ ) from March 2014 to March 2015. The farm covers a total surface of $\sim 8000 \mathrm{~m}^{2}$ and encompasses 23 floating cages arranged in 2 rows containing sea bass Dicentrarchus labrax (Linnaeus, 1758) and sea bream Sparus aurata, Linnaeus, 1758, with a total annual production exceeding $300 \mathrm{t}$. The farm is located in a semi-enclosed and sheltered area characterized by limited hydrodynamic circulation and shallow depth (max depth $\sim 10 \mathrm{~m}$ ). Consequently, a large amount of organic matter, in the form of uneaten food and feces of the reared fish, accumulates on the sea floor under the cages, a phenomenon that appears to cause a progressive transformation of the benthic substrate into a muddy black sediment (Ape et al. 2019). In addition, the area is periodically (from August to October) affected by hypoxia phenomena, with oxygen concentration dropping within the sublethal (sensu Sokolova et al. 2012) range $\left(\sim 2 \mathrm{mg} \mathrm{l}^{-1}\right)$ in aquatic invertebrates (Giomi \& Pörtner, 2013). In March 2014 (T0), 180 cement fiber panels $(10 \times 10 \mathrm{~cm}), 5$ to $10 \mathrm{~mm}$ thick, were placed close to 2 fish cages within the fish farm and divided in 2 groups. 
The first group (Group A) was positioned to follow the successional stages of biofouling and was composed of 144 panels. The colonization stages of biofouling were monitored throughout the study period by collecting 36 panels every 3 mo (T1: June 2014; T2: September 2014; T3: December 2014; T4: March 2015). The second group of panels (Group B) was used to investigate seasonal recruitment processes and was composed of 36 panels which were replaced every 3 mo with new (i.e. uncolonized) ones. This allowed us to investigate whether seasonality plays a role in the response of the assemblage (see Table 1 for an overview of sampling times). Cement fiber was chosen as it appears to be more suitable for settlement of natural fouling than more common substrata (e.g. glass or PVC; Chase 2015) traditionally used in monthly or annual samplings (Terlizzi \& Faimali 2010). Six panels were attached to $200 \mathrm{~cm}$ long vertical nautical ropes and the distance between panels on a single rope was $30 \mathrm{~cm}$. A total of 48 ropes were used for the whole sampling period.

Water temperature $\left({ }^{\circ} \mathrm{C}\right)$ and DO $\left(\mathrm{mg} \mathrm{l}^{-1}\right)$ were continuously monitored before and during the whole sampling period by means of thermo and DO loggers (Type 22 iButton and HOBO U26 Dissolved Oxygen Data Logger, respectively). Loggers were placed in each cage at a depth of ca. $1 \mathrm{~m}$ and data recorded were used to set laboratory experimental treatments (see Text S1 and Figs. S1-S4 in the Supplement at www.int-res.com/articles/suppl/q012p011_supp.pdf). Every time we removed panels, water samples were collected and the amount of total suspended matter and its fraction were quantified to characterize the trophic condition of the target system (Table $\mathrm{S} 1$; Figs. S5-S6).

\subsection{Ecophysiology and community composition of biofouling}

Every 3 months (i.e. T1, T2, T3 and T4), 36 panels from each group (A and B) were removed from the rope and brought back to the laboratory (Laboratory of Ecology, University of Palermo, Italy), where they were maintained undisturbed for $24 \mathrm{~h}$ to reduce the stress due to manipulation. Then the panels were randomly divided into 6 groups of 6 panels and conditioned to 3 different DO concentrations (i.e. normoxic, intermediate $\left[4 \mathrm{mg} \mathrm{l}^{-1}\right]$ and hypoxic $\left[2 \mathrm{mg} \mathrm{l}^{-1}\right]$ conditions), mimicking the natural DO profile occur- ring within the study site, for a period of 6 and $24 \mathrm{~h}$. Additionally, measurements of community clearance rate $(\mathrm{CR})$ and metabolic rate, by using respiration rate (RR) as a proxy, were performed at 6 and $24 \mathrm{~h}$ after the beginning of each treatment.

Both CR and RR were measured to get values at community level using methods described in several studies designed for the individual analysis of functional traits (e.g. Sarà et al. 2000, 2008, 2013, 2014, Ezgeta-Balić et al. 2011, Giomi et al. 2016). In short, we placed 1 panel in a beaker containing $2.5 \mathrm{l}$ of filtered seawater. Beakers were placed on heated stirring base plates to keep the water thermo-regulated, mixed and oxygenated throughout the experimental sessions. For CR measurements, algal cells (Isochrysis galbana, Parke 1949) were added to each beaker at an initial concentration of 25000 cells $\mathrm{ml}^{-1}$, and aliquots of $20 \mathrm{ml}$ were sampled from every beaker at $30 \mathrm{~min}$ intervals over a period of $2 \mathrm{~h}$. The choice of the algal species, concentration and timing have been demonstrated to be adequate to measure filtration rate not only in bivalves (e.g. Widdows \& Staff 2006), but also in other active filter-feeders such as ascidians and bryozoans (e.g. Pascoe et al. 2007, Montalto et al. 2017). The decline in I. galbana cell concentration was monitored using a Model Z2 Coulter Counter (Beckman Coulter). Before starting with measurements of RR, beakers were completely wrapped in black cellophane in order to make the contribution of primary production negligible. The decline in oxygen concentration was measured using a calibrated oxygen fibreglass sensor connected to a data logger (PyroScience Firesting $\mathrm{O}_{2}$ ) and continuously recorded for at least $1 \mathrm{~h}$ after waiting $10 \mathrm{~min}$, during which a more rapid decline in oxygen caused by a disturbance of the sensor's temperature equilibration is usually recorded (Svendsen et al. 2016).

Once physiological measurements on panels treated with different levels of oxygen had been performed, encrusting benthic communities were gently scraped from the panel surface and the animal component separated from the algal component and fixed in 
$70 \%$ ethanol. Then, benthic specimens were gently washed over a $500 \mu \mathrm{m}$ sieve, sorted from the abiotic components (mostly calcareous tubes) and identified to the lowest taxonomic level. Both algae and animals were separately weighted to determine the biomass (expressed as g wet weight [WW]) and to standardize physiological measurements. Specifically, CR measurements have been standardized by taking into account only the animal component, while the whole community biomass is considered in estimates of metabolic performances (Sarà et al. 2000, 2008, 2013, 2014, Ezgeta-Balić et al. 2011, Giomi et al. 2016).

\subsection{Statistical analysis}

Due to the loss of some panels in both groups (a total of 10 in Group A and 27 in Group B) during the autumn season (T3), the experimental design became unbalanced, and therefore data were analysed through PERMANOVA (Anderson 2001) using Euclidean distance and 9999 permutations. Further, the sets of panels collected at the first sampling period (T1) from both groups were excluded from the analysis because they were characterized by the presence of algae only and, as a consequence, filtration activity was unable to be measured. Thus, season (3 levels: T2, T3, T4), $\mathrm{O}_{2}$ treatment (3 levels: control, $4 \mathrm{mg} \mathrm{l}^{-1}$, $2 \mathrm{mg} \mathrm{l}^{-1}$ ), and exposure time (2 levels: $6 \mathrm{~h}, 24 \mathrm{~h}$ ) were treated as fixed factors in the experimental design, and with the exception of T3, 6 replicates for each level (i.e. oxygen treatments and exposure times) were used (i.e. a total of 36 replicates for each group for each sampling time). PERMANOVA was carried out by using the PRIMER software (version 6.0).

\section{RESULTS}

\subsection{Ecophysiological measurements: CR and RR}

Overall, standardized CRs for Group A ranged between 1.22 and $3.01 \mathrm{l} \mathrm{h}^{-1} \mathrm{~g} \mathrm{WW}^{-1}$, showing significant differences among seasons (Table 2a), while in Group B, measurements varied between 0.50 and $5.62 \mathrm{l} \mathrm{h}^{-1} \mathrm{~g} \mathrm{WW}^{-1}$ (Fig. 1). Despite differences found in both biomass and composition of benthic fauna (see Section 3.2) recruited on panels belonging to Group $B$, results showed similar $\mathrm{CR}$ of communities when both oxygen levels and exposure time varied $(\mathrm{p}>$ 0.05 ; Table $2 b)$. On the contrary, when the algal components were included, there were significant differences in RRs of the whole communities among differ- ent seasons (Table 2b). Specifically, as showed in Fig. 2, communities recruited at T2 showed significantly higher RRs than those measured in communities settled at T3 and T4, with average ( \pm SE) RRs of $6.79 \pm$ $0.65 \mu \mathrm{mol} \mathrm{O} \mathrm{h}^{-1} \mathrm{~g} \mathrm{WW}^{-1}, 2.94 \pm 0.36 \mu \mathrm{mol} \mathrm{O} \mathrm{h}^{-1} \mathrm{~g}$ $\mathrm{WW}^{-1}$ and $4.27 \pm 0.50 \mu \mathrm{mol} \mathrm{O} \mathrm{O}^{-1} \mathrm{~g} \mathrm{WW}^{-1}$, respectively. Analogously, in Group A panels, both CR and RR were significantly different among seasons (Table 2). Accordingly, CR and RR in assemblages recruited after 6 mo of submersion were higher than those in communities after 9 and 12 mo submersion.

No panels from either group showed significant differences in physiological measurements when oxygen availability and/or exposure time varied (Table 2). Exceptions were represented by CRs measured at T2 and T3 ( $\mathrm{p}<0.05)$ under normoxic conditions, at T2 and T4 $(\mathrm{p}<0.001)$ under the hypoxic conditions and the treatments performed at intermediate oxygen concentration (i.e. $4 \mathrm{mg} \mathrm{l}^{-1}$ ), where CRs of communities collected at T2 were significantly higher than in assemblages collected at T3 $(p<0.01)$ and T4 $(p<0.05)$ (Table 3).

\subsection{Fouling communities: biomass and composition}

Crustaceans (mainly barnacles and amphipods), tunicates (mainly ascidians), polychaetes and seaweeds were the components of fouling commonly observed on the panels (Fig. 3). Overall results showed that the average biomass of Group A was higher than that of Group B measured at each period, with values ranging, respectively, between 15.45 and $46.01 \mathrm{~g} \mathrm{WW}$ and 4.85 and $18.96 \mathrm{~g}$ WW. Also, as shown in Fig. 4, the average \% biomass of algae in Group B was higher (more than $50 \%$ of the total biomass on each panel) than animal biomass when compared with that measured on panels of Group A. Indeed, in the latter group, longer submersion times resulted in a reduction of algal biomass up to $30 \%$ of the mean total wet weight after 1 yr of deployment. PERMANOVA showed significant differences in the biomass of communities recruited during the different seasons in both groups of panels. On the other hand, there were no significant differences in panels of both groups used during every experimental treatment (i.e. when both oxygen levels and exposure time varied; Table 3).

The pairwise comparison (Table 3 ) for panels colonized quarterly (i.e. Group B) showed that benthic biomass (animal + algae) recruited between T3 and T4 was significantly lower than that measured in the other 2 periods, with mean $( \pm \mathrm{SE})$ values of $4.12 \pm 0.98 \mathrm{~g}$ 
Table 2. PERMANOVA of results and group analysis for standardized (st) clearance rate $\left(\mathrm{CR}_{1} 1 \mathrm{~h}^{-1} \mathrm{~g} \mathrm{WW}^{-1}\right)$ and respiration rate $\left(\mathrm{RR}, \mu \mathrm{mol} \mathrm{l}^{-1} \mathrm{~h}^{-1} \mathrm{~g} \mathrm{WW}^{-1}\right.$ ) during different sampling periods. (a) Panels collected after 6, 9 and 12 mo (Group A); (b) = 3 mo old panels submerged during different seasons (Group B). SE: season; TREAT: $\mathrm{O}_{2}$ treatment, EXP: exposure time; RES: residuals. See Table 1 for further definitions

\begin{tabular}{|c|c|c|c|c|c|c|c|c|c|c|}
\hline Source & $\mathrm{df}$ & SS & MS & Pseudo- $F$ & $\mathrm{P}($ perm $)$ & $\begin{array}{l}\text { Unique } \\
\text { perms }\end{array}$ & Groups & $t$ & $\mathrm{P}($ perm$)$ & $\begin{array}{l}\text { Unique } \\
\text { perms }\end{array}$ \\
\hline \multicolumn{11}{|l|}{ (a) } \\
\hline \multicolumn{11}{|l|}{ CRst } \\
\hline $\mathrm{SE}$ & 2 & 53.93 & 26.97 & 12.24 & 0.0002 & 9952 & T2, T3 & 3.67 & 0.0007 & 9848 \\
\hline TREAT & 2 & 11.85 & 5.92 & 2.69 & 0.0712 & 9951 & $\mathrm{~T} 2, \mathrm{~T} 4$ & 3.76 & 0.0001 & 9839 \\
\hline EXP & 1 & 0.68 & 0.68 & 0.31 & 0.5963 & 9860 & T3, T4 & 0.15 & 0.1502 & 9863 \\
\hline $\mathrm{SE} \times \mathrm{TREAT}$ & 4 & 22.32 & 5.58 & 2.53 & 0.0466 & 9951 & & & & \\
\hline $\mathrm{SE} \times \mathrm{EXP}$ & 2 & 1.54 & 0.77 & 0.35 & 0.7132 & 9944 & & & & \\
\hline TREAT $\times$ EXP & 2 & 5.84 & 2.92 & 1.32 & 0.266 & 9964 & & & & \\
\hline $\mathrm{SE} \times \mathrm{TREAT} \times \mathrm{EXP}$ & 4 & 10.5 & 2.63 & 1.19 & 0.3232 & 9957 & & & & \\
\hline RES & 77 & 169.64 & 2.2 & & & & & & & \\
\hline \multicolumn{11}{|l|}{ RRst } \\
\hline $\mathrm{SE}$ & 2 & 307.52 & 153.76 & 22.21 & 0.0001 & 9941 & T2, T3 & 4.25 & 0.0001 & 9861 \\
\hline TREAT & 2 & 14.21 & 7.1 & 1.03 & 0.3716 & 9940 & $\mathrm{~T} 2, \mathrm{~T} 4$ & 5.36 & 0.0001 & 9861 \\
\hline EXP & 1 & 26.27 & 26.27 & 3.8 & 0.0514 & 9851 & T3, T4 & 1.52 & 0.1328 & 9831 \\
\hline $\mathrm{SE} \times \mathrm{TREAT}$ & 4 & 44.92 & 11.23 & 1.62 & 0.165 & 9950 & & & & \\
\hline $\mathrm{SE} \times \mathrm{EXP}$ & 2 & 26.43 & 13.21 & 1.91 & 0.1553 & 9957 & & & & \\
\hline TREAT $\times$ EXP & 2 & 34.49 & 17.24 & 2.49 & 0.0795 & 9951 & & & & \\
\hline $\mathrm{SE} \times \mathrm{TREAT} \times \mathrm{EXP}$ & 4 & 46.7 & 11.67 & 1.69 & 0.157 & 9946 & & & & \\
\hline RES & 74 & 512.2 & 6.92 & & & & & & & \\
\hline \multicolumn{11}{|l|}{ (b) } \\
\hline \multicolumn{11}{|l|}{ CRst } \\
\hline $\mathrm{SE}$ & 2 & 194.21 & 97.1 & 1.74 & 0.1619 & 9937 & & & & \\
\hline TREAT & 2 & 46.87 & 23.44 & 0.42 & 0.5381 & 9931 & & & & \\
\hline EXP & 1 & 9.25 & 9.25 & 0.17 & 0.6432 & 9800 & & & & \\
\hline $\mathrm{SE} \times \mathrm{TREAT}$ & 4 & 66.09 & 16.52 & 0.3 & 0.8455 & 9942 & & & & \\
\hline $\mathrm{SE} \times \mathrm{EXP}$ & 2 & 176.15 & 88.07 & 1.58 & 0.1693 & 9940 & & & & \\
\hline TREAT $\times$ EXP & 2 & 9 & 4.5 & 0.08 & 0.8923 & 9929 & & & & \\
\hline $\mathrm{SE} \times \mathrm{TREAT} \times \mathrm{EXP}$ & 4 & 186.25 & 46.56 & 0.83 & 0.3882 & 9939 & & & & \\
\hline RES & 53 & 2959.7 & 55.84 & & & & & & & \\
\hline \multicolumn{11}{|l|}{ RRst } \\
\hline $\mathrm{SE}$ & 2 & 169.54 & 84.77 & 8.33 & 0.002 & 9961 & T2, T3 & 3.18 & 0.0053 & 9808 \\
\hline TREAT & 2 & 18.65 & 9.32 & 0.92 & 0.4081 & 9943 & $\mathrm{~T} 2, \mathrm{~T} 4$ & 2.8 & 0.0073 & 9845 \\
\hline EXP & 1 & 0.01 & 0.01 & 0 & 0.9828 & 9829 & T3, T4 & 1.98 & 0.0620 & 9834 \\
\hline $\mathrm{SE} \times \mathrm{TREAT}$ & 4 & 15.68 & 3.92 & 0.39 & 0.8136 & 9945 & & & & \\
\hline $\mathrm{SE} \times \mathrm{EXP}$ & 2 & 26.24 & 13.12 & 1.29 & 0.2839 & 9948 & & & & \\
\hline TREAT $\times$ EXP & 2 & 22.23 & 11.12 & 1.09 & 0.3448 & 9948 & & & & \\
\hline $\mathrm{SE} \times \mathrm{TREAT} \times \mathrm{EXP}$ & 4 & 26.27 & 6.57 & 0.65 & 0.63 & 9950 & & & & \\
\hline RES & 56 & 569.97 & 10.18 & & & & & & & \\
\hline
\end{tabular}

WW (T2), $7.89 \pm 1.95 \mathrm{~g} \mathrm{WW}$ (T3) and $0.37 \pm 0.09 \mathrm{~g} \mathrm{WW}$ (T4). Within the animal component, the largest number of taxonomic groups (i.e. 7; Fig. 3b) were identified in the post-summer panels (T2), where the prevailing biomass comprised bryozoa, polychaetes, ascidians and crustaceans, whereas after the autumn and winter periods (T3 and T4), panels were mainly colonized by polychaetes and crustaceans, which in both cases accounted for more than $90 \%$ of mean animal biomass.

In Group A, wet mass of animal assemblages increased with increasing time of submersion, with postsummer WW significantly lower $(p<0.001$; Table 3$)$ and corresponding to a recruitment period of $6 \mathrm{mo}$ (i.e. T2). Similarly, the number of taxonomic groups varied with length of submersion, with a total of 6 groups (Fig. 3a) identified in 6 and 9 mo old panels (at T2 and T3) and of 9 groups distinguished in panels submersed for $1 \mathrm{yr}$ (at T4) (Fig. 3b). After this time of exposure, the benthic community settling on the panels reached the highest number of species and was mainly dominated by epibenthic incrusting species such as the tunicate Styela plicata (Lesueur, 1823), bryozoans (Cryptosula spp.), sponges (Halicondria spp.), barnacles and serpulid tubeworms (Hydroides spp.; see Table S2 for more details). High numbers of both errant (Nereis pelagica Linnaeus, 1758) and 

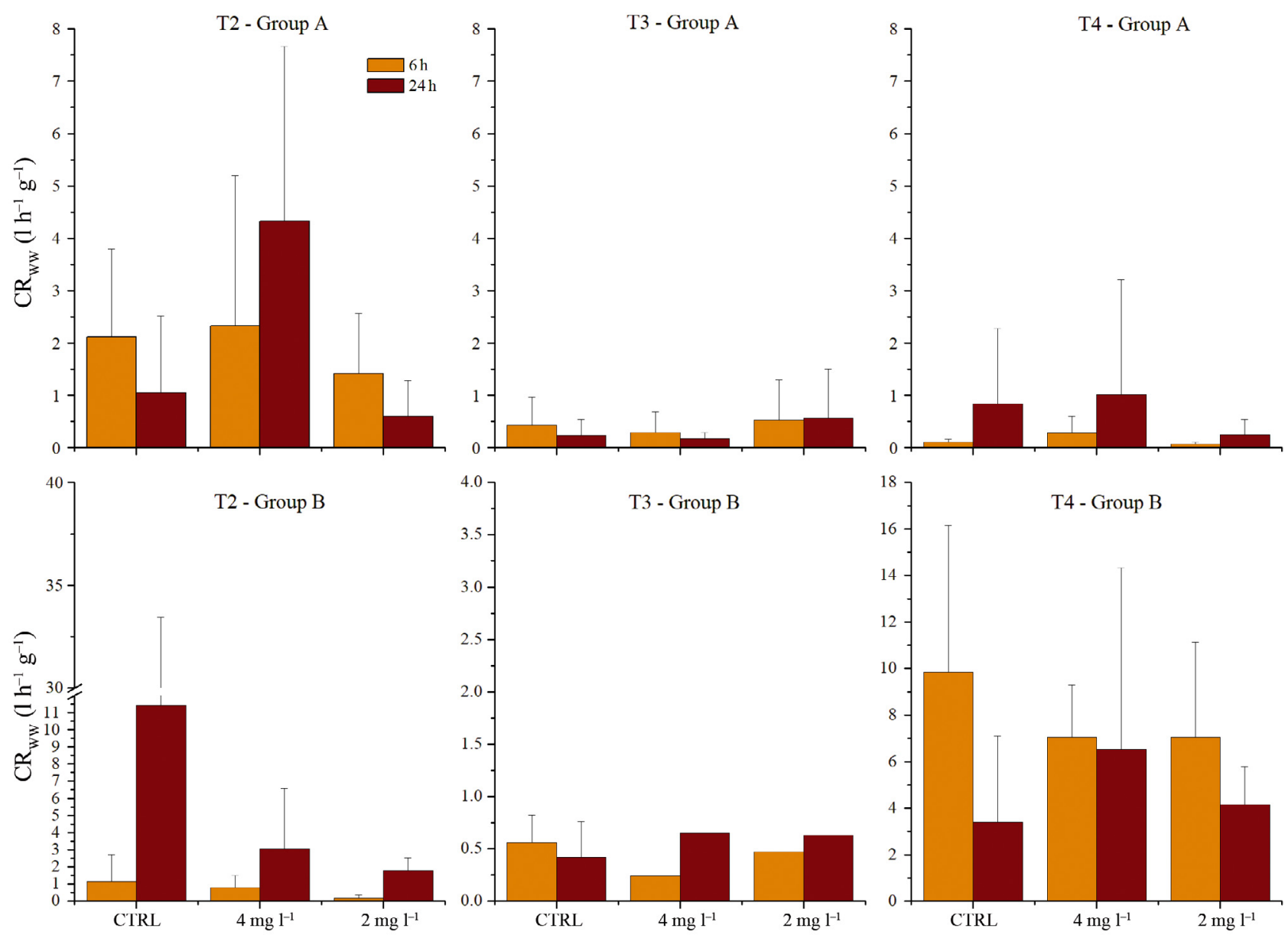

Fig. 1. Standardized clearance rates (CR) of biofouling communities at varying levels of oxygen availability after 6 and $24 \mathrm{~h}$ of treatment (CTRL [well-saturated], $4 \mathrm{mg} \mathrm{l}^{-1}$ and $2 \mathrm{mg} \mathrm{l}^{-1}$ ) for panels collected after 6, 9 and 12 mo submersion (Group A) (at T2, T3 and T4, respectively) and panels submersed for 3 mo and collected at T2, T3 and T4 (Group B). WW: wet weight. See Table 1 for dates

sedentary polychaetes (e.g. Spirobranchus sp.) were observed. The filter feeder tubiculous Sabellariidae Branchiomma bombyx was the most frequent sedentary polychaete found on the panels. Among the vagile fauna, crustacean species (mainly amphipods and tanaids) and the echinoderm Ophiothrix fragilis were most abundant (Mangano et al. 2019). Tubedwelling amphipods and several introduced species were also recorded (see Text S2 and Table S2). Algal biomass in both groups of panels was significantly different among seasons (Table 3) except for algal biomass in panels of Group A submersed for 6 and 12 mo, where the pairwise comparison yielded no significant differences ( $p>0.05$; Table 3$)$.

\section{DISCUSSION}

Biofouling is a recurring issue in aquaculture worldwide, especially when activities are geographi- cally located in suboptimal sites such as enclosed sites, where the assimilative capacity (sensu Chopin 2010) can be frequently exceeded. Nevertheless, our results show that biofouling can also have an ecologically facilitating role, thanks to the active (and massive) filtering capacity of assemblages encrusting artifical substrata. Indeed, regardless of the composition of the species succeeding in the panels, the positive clearance rates confirmed a continuous activity of particle removal by structured communities. Accordingly, the high clearance rates measured in recruitment panels collected at T2 (summer) and T4 (winter), compared to those collected at T3, i.e. autumn, suggested that the environmental physicalchemical conditions were able to play a role in affecting particle removal dynamics. In fact, other than crustaceans, biofouling in both groups of panels was mainly composed of the ascidian Styela plicata, whose recruitment may be promoted by an optimal combination of thermal $\left(22.23 \pm 0.03^{\circ} \mathrm{C}\right)$ and trophic 

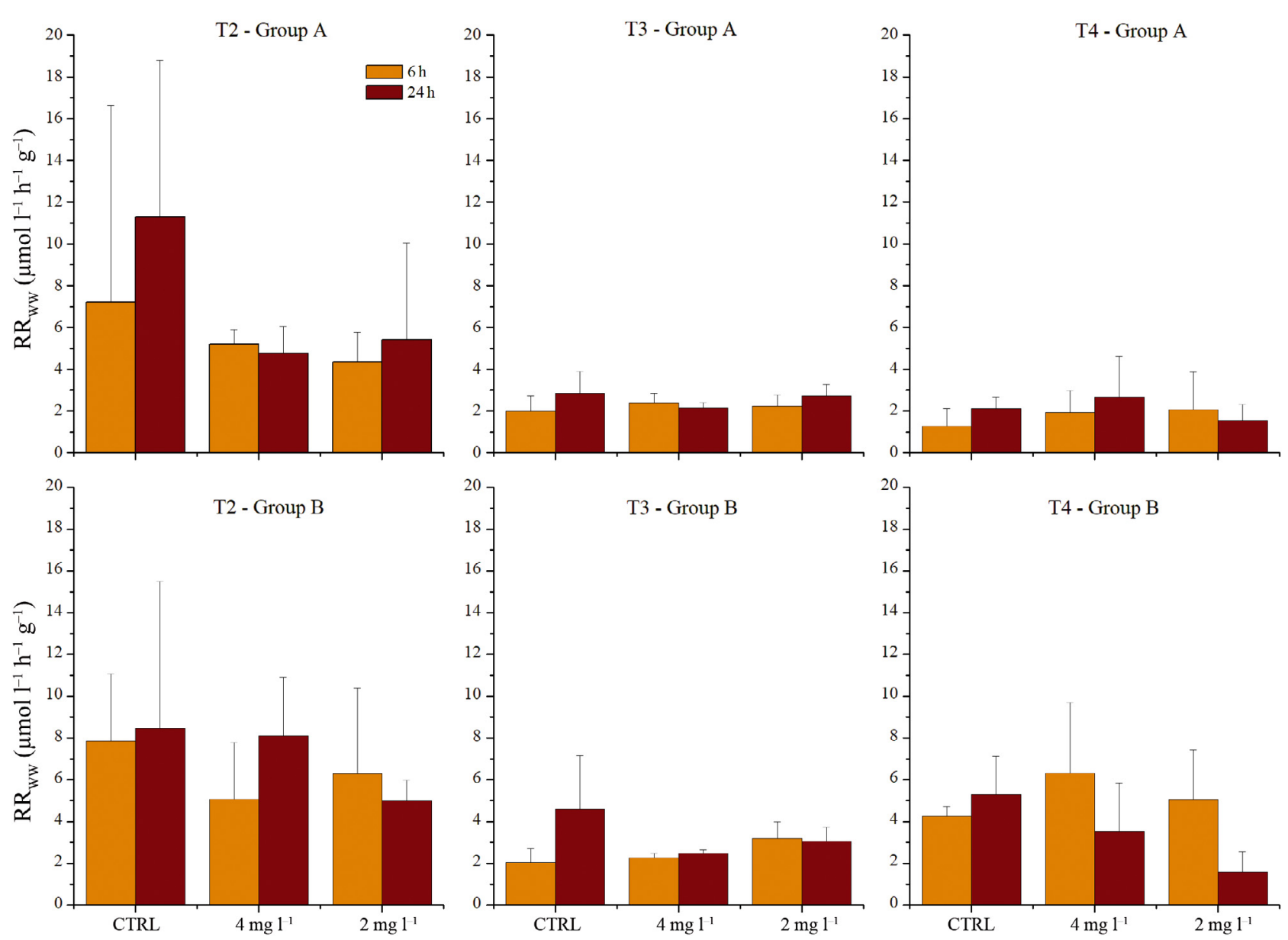

Fig. 2. Standardized respiration rates (RR) of biofouling communities at varying levels of oxygen availability. See Fig. 1 and Table 1 for further details

conditions, together with a favourable relationship between oxygen uptake and body size (sensu Montalto et al. 2017), by disavantaging the presence of other filter-feeders such as hydrozoans and porifers. Ascidians thus seem to take an advantage of local conditions, and this makes them 'winners' among other filter feeders. The inhibition of settlement or recruitment by resident adults has been described by several authors (e.g. Tyrrell \& Byers 2007) as a result of competition for space (altering the possibility of adhesion by the larvae) and/or chemical inhibition mechanisms (e.g. Davis 1991, Paul \& Puglisi 2004).

Surprisingly, oxygen consumption was also affected by factors other than environmental oxygen availability. As resulted from the PERMANOVA carried out on $\mathrm{RR}$, the experimental oxygen treatments did not impair assemblage response, while the analysis suggests that variations in the magnitude of the response are a function of the biomass recruiting at different seasons. Nonetheless, the sequence in which fouling organisms recruit is influenced prima- rily by seasonal temperature fluctuations, as temperature affects reproductive cycle and subsequent larval release and development of marine organisms (Duarte 2007). However there are several data showing that some stages of succession can be influenced by the previously established taxa (Lezzi et al. 2018). Hydroids, for example, seem be able to prepare a micro-environment suitable for bryozoans (Menon \& Nair 1971, Khalaman 2001) and mussels can be more successful on substrates already occupied by ascidians and hydroids (Dean \& Hurd 1980), while the presence of filter feeder worms seems to be more related to a high availability of food in the environment. As shown in Fig. 3, indeed, there was an increase in biomass during autumn, which corresponds at these latitudes to the period of highest concentrations of both chl $a$ and suspended organic matter (Table S1, Figs. S5 \& S6). Finally, some groups like ascidians, amphipods and polychaetes, being able to efficiently use the organic fraction of suspended matter and aquaculture wastes, are known for reducing 
Table 3. PERMANOVA of results and group analysis for wet biomass (WW, g); animal (WW an), algal (WW veg) and total (WW tot); during different sampling periods. (a) Panels collected after 6, 9 and 12 mo (Group A); (b) 3 mo old panels submerged during different seasons (Group B). SE: season; TREAT: $\mathrm{O}_{2}$ treatment, EXP: exposure time; RES: residuals. See Table 1 for further definitions

\begin{tabular}{|c|c|c|c|c|c|c|c|c|c|c|}
\hline Source & $\mathrm{df}$ & SS & MS & Pseudo- $F$ & $\mathrm{P}($ perm $)$ & $\begin{array}{l}\text { Unique } \\
\text { perms }\end{array}$ & Groups & $t$ & $\mathrm{P}($ perm $)$ & $\begin{array}{l}\text { Unique } \\
\text { perms }\end{array}$ \\
\hline \multicolumn{11}{|l|}{ (a) } \\
\hline \multicolumn{11}{|l|}{ WW an } \\
\hline SE & 2 & 12010 & 6005.2 & 21.75 & 0.0001 & 9958 & T2, T3 & 6.4098 & 0.0001 & 9838 \\
\hline TREAT & 2 & 53.32 & 26.66 & 0.1 & 0.9103 & 9946 & $\mathrm{~T} 2, \mathrm{~T} 4$ & 6.1745 & 0.0001 & 9854 \\
\hline EXP & 1 & 83.89 & 83.89 & 0.3 & 0.5976 & 9844 & $\mathrm{~T} 3, \mathrm{~T} 4$ & 1.8811 & 0.0702 & 9842 \\
\hline $\mathrm{SE} \times \mathrm{TREAT}$ & 4 & 1890.5 & 472.61 & 1.71 & 0.1571 & 9961 & & & & \\
\hline $\mathrm{SE} \times \mathrm{EXP}$ & 2 & 519.44 & 259.72 & 0.94 & 0.4034 & 9955 & & & & \\
\hline TREAT $\times$ EXP & 2 & 309.01 & 154.51 & 0.56 & 0.5815 & 9950 & & & & \\
\hline $\mathrm{SE} \times \mathrm{TREAT} \times \mathrm{EXP}$ & 4 & 544.81 & 136.2 & 0.49 & 0.7486 & 9949 & & & & \\
\hline RES & 77 & 21259 & 276.08 & & & & & & & \\
\hline \multicolumn{11}{|l|}{ WW veg } \\
\hline $\mathrm{SE}$ & 2 & 1680.8 & 840.42 & 23.18 & 0.0001 & 9950 & T2, T3 & 6.9567 & 0.0001 & 9821 \\
\hline TREAT & 2 & 68.13 & 34.07 & 0.94 & 0.3898 & 9947 & $\mathrm{~T} 2, \mathrm{~T} 4$ & 1.5111 & 0.1368 & 9830 \\
\hline EXP & 1 & 31.43 & 31.43 & 0.87 & 0.3528 & 9825 & T3, T4 & 5.3018 & 0.0001 & 9822 \\
\hline $\mathrm{SE} \times \mathrm{TREAT}$ & 4 & 57.39 & 14.35 & 0.4 & 0.8114 & 9962 & & & & \\
\hline $\mathrm{SE} \times \mathrm{EXP}$ & 2 & 194.93 & 97.47 & 2.69 & 0.0723 & 9951 & & & & \\
\hline TREAT $\times$ EXP & 2 & 97.7 & 48.85 & 1.35 & 0.2644 & 9958 & & & & \\
\hline $\mathrm{SE} \times \mathrm{TREAT} \times \mathrm{EXP}$ & 4 & 127.73 & 31.93 & 0.88 & 0.4814 & 9955 & & & & \\
\hline RES & 77 & 2792.3 & 36.26 & & & & & & & \\
\hline \multicolumn{11}{|l|}{ WW tot } \\
\hline SE & 2 & 17507 & 8753.5 & 27.4 & 0.0001 & 9933 & T2, T3 & 9.0983 & 0.0001 & 9833 \\
\hline TREAT & 2 & 126.74 & 63.37 & 0.2 & 0.8269 & 9937 & $\mathrm{~T} 2, \mathrm{~T} 4$ & 6.4547 & 0.0001 & 9813 \\
\hline EXP & 1 & 91.96 & 91.96 & 0.29 & 0.6024 & 9856 & T3, T4 & 0.2922 & 0.7726 & 9841 \\
\hline $\mathrm{SE} \times \mathrm{TREAT}$ & 4 & 1264.5 & 316.13 & 0.99 & 0.4185 & 9952 & & & & \\
\hline $\mathrm{SE} \times \mathrm{EXP}$ & 2 & 227.79 & 113.9 & 0.36 & 0.7114 & 9954 & & & & \\
\hline TREAT $\times$ EXP & 2 & 327.45 & 163.73 & 0.51 & 0.6194 & 9955 & & & & \\
\hline $\mathrm{SE} \times \mathrm{TREAT} \times \mathrm{EXP}$ & 4 & 500.82 & 125.21 & 0.39 & 0.8169 & 9944 & & & & \\
\hline RES & 74 & 23645 & 319.53 & & & & & & & \\
\hline \multicolumn{11}{|l|}{ (b) } \\
\hline \multicolumn{11}{|l|}{ WW an } \\
\hline SE & 2 & 360.68 & 180.34 & 7.49 & 0.0057 & 9936 & T2, T3 & 1.3413 & 0.1891 & 9815 \\
\hline TREAT & 2 & 47.84 & 23.92 & 0.99 & 0.3502 & 9956 & $\mathrm{~T} 2, \mathrm{~T} 4$ & 3.0348 & 0.003 & 9818 \\
\hline EXP & 1 & 0.13 & 0.13 & 0.01 & 0.939 & 9832 & T3, T4 & 6.1396 & 0.0007 & 9833 \\
\hline $\mathrm{SE} \times \mathrm{TREAT}$ & 4 & 23.44 & 5.86 & 0.24 & 0.882 & 9952 & & & & \\
\hline $\mathrm{SE} \times \mathrm{EXP}$ & 2 & 3.84 & 1.92 & 0.08 & 0.9159 & 9947 & & & & \\
\hline TREAT $\times$ EXP & 2 & 36.3 & 18.15 & 0.75 & 0.4219 & 9950 & & & & \\
\hline $\mathrm{SE} \times \mathrm{TREAT} \times \mathrm{EXP}$ & 4 & 91.05 & 22.76 & 0.94 & 0.4228 & 9936 & & & & \\
\hline RES & 53 & 1276.9 & 24.09 & & & & & & & \\
\hline \multicolumn{11}{|l|}{ WW veg } \\
\hline $\mathrm{SE}$ & 2 & 328.38 & 164.19 & 31.38 & 0.0001 & 9960 & T2, T3 & 3.2475 & 0.0021 & 9850 \\
\hline TREAT & 2 & 16.08 & 8.04 & 1.54 & 0.2261 & 9943 & $\mathrm{~T} 2, \mathrm{~T} 4$ & 5.6918 & 0.0001 & 9834 \\
\hline EXP & 1 & 3.19 & 3.19 & 0.61 & 0.4391 & 9850 & T3, T4 & 10.963 & 0.0001 & 9860 \\
\hline $\mathrm{SE} \times \mathrm{TREAT}$ & 4 & 12.36 & 3.09 & 0.59 & 0.6689 & 9957 & & & & \\
\hline $\mathrm{SE} \times \mathrm{EXP}$ & 2 & 10.11 & 5.06 & 0.97 & 0.3876 & 9944 & & & & \\
\hline TREAT $\times$ EXP & 2 & 24.96 & 12.48 & 2.39 & 0.1036 & 9944 & & & & \\
\hline $\mathrm{SE} \times \mathrm{TREAT} \times \mathrm{EXP}$ & 4 & 8.86 & 2.22 & 0.42 & 0.7935 & 9954 & & & & \\
\hline RES & 53 & 277.3 & 5.23 & & & & & & & \\
\hline \multicolumn{11}{|l|}{ WW tot } \\
\hline SE & 2 & 1513.7 & 756.87 & 18.36 & 0.0001 & 9941 & T2, T3 & 2.2301 & 0.0313 & 9809 \\
\hline TREAT & 2 & 35.61 & 17.81 & 0.43 & 0.6479 & 9935 & $\mathrm{~T} 2, \mathrm{~T} 4$ & 4.3201 & 0.0002 & 9840 \\
\hline EXP & 1 & 11.71 & 11.71 & 0.28 & 0.6056 & 9849 & T3, T4 & 9.8455 & 0.0001 & 9839 \\
\hline $\mathrm{SE} \times \mathrm{TREAT}$ & 4 & 110.18 & 27.55 & 0.67 & 0.6219 & 9937 & & & & \\
\hline $\mathrm{SE} \times \mathrm{EXP}$ & 2 & 7.52 & 3.76 & 0.09 & 0.9118 & 9953 & & & & \\
\hline TREAT $\times$ EXP & 2 & 104.02 & 52.01 & 1.26 & 0.2919 & 9948 & & & & \\
\hline $\mathrm{SE} \times \mathrm{TREAT} \times \mathrm{EXP}$ & 4 & 98.01 & 24.5 & 0.59 & 0.6727 & 9958 & & & & \\
\hline RES & 56 & 2308.8 & 41.23 & & & & & & & \\
\hline
\end{tabular}



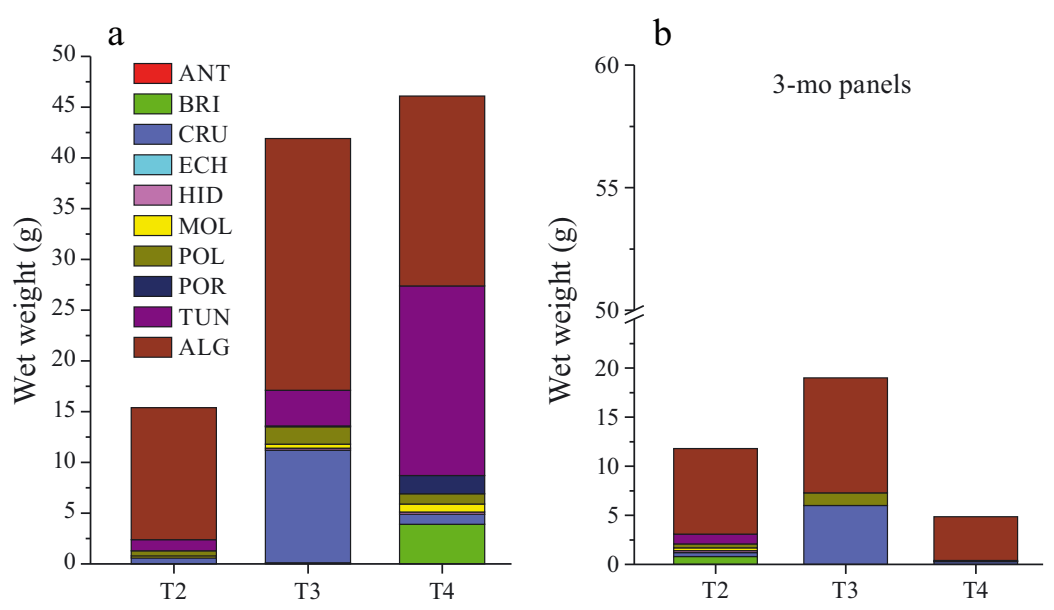

Fig. 3. Mean wet weight and relative composition of biofouling communities on submersed panels. (a) Assemblages recruited on panels left to colonize for 6, 9 and 12 mo (Group A) (collected at T2, T3 and T4, respectively) and (b) panels submersed for 3 mo and collected at T2, T3 and T4 (Group B). ANT: Anthozoa; BRI: Bryozoa; CRU: Crustacea; ECH: Echinodermata; HID: Hydrozoa; MOL: Mollusca; POL: Polychaeta; POR: Porifera; TUN: Tunicata; ALG: Algae. See Table 1 for dates

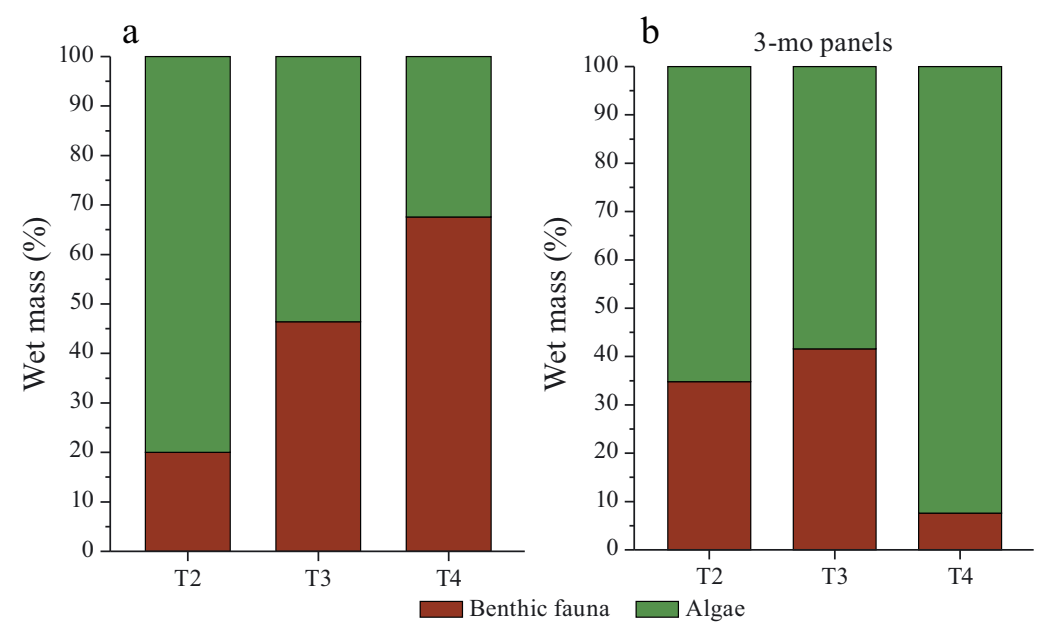

Fig. 4. Percentage contribution of macrofaunal community and algae assemblages recruited on submersed panels. (a) Assemblages recruited on panels left to colonize for 6, 9 and 12 mo (Group A) (collected at T2, T3 and T4, respectively) and (b) panels submersed for 3 mo and collected at T2, T3 and T4 (Group B). See Table 1 for dates

competition for other types of resources such as phytoplankton (Bracken et al. 2012). This in turn could positively affect the presence of bivalves, which rely on a diet of fresh organic matter such as phytoplankton, may represent an additional set of organisms contributing to particle removal (Newell 2004) with a consequent improvement of water quality (Manganaro et al. 2009, Sarà et al. 2009, Troell et al. 2009).

However, in the last decade, the optimization of environmental conditions and aquaculture activities has led to the need to investigate and propose alternative solutions in order to advance in the sustainability of aquaculture (Troell et al. 2003, Chopin 2010). Within this context, many of the species found on the panels in our study are by-products of aquaculture and could be employed in aquaculture systems as a novel bioremediation technology to reduce waste materials and restore water quality. On the other hand, while higher macroalgae (e.g. Gracilaria sp.) and mussels are well known co-cultured species for the removal of nitrogen and phosphorus, phytoplankton and suspended particle with the advantage that they are subsequently reused for food purposes, other organisms may find a further application in other disciplines that are not directly linked to a food trade (e.g. Hamed et al. 2015). To date, few studies have provided evidence for the capability of biofouling to remove aquaculture waste and employed different organisms as potential candidates for bioremediation in an aquaculture farming scenario. For example, several authors have demonstrated the potential of amphipod cultures associated with integrated multi-trophic aquaculture systems, demonstrating the suitability of the amphipod-based product for use as a natural ingredient in aquafeed compositions (e.g Fernandez-Gonzalez et al. 2018). Further, Licciano et al. (2005) estimated a filtration capacity of $0.28 \mathrm{~m}^{3} \mathrm{~g}$ dry weight $(\mathrm{DW})^{-1} \mathrm{~d}^{-1}$ in Sabella spallanzanii, while Pierri (2007) reported a filtered volume of $1.1 \mathrm{~m}^{3} \mathrm{~g}$ $\mathrm{DW}^{-1} \mathrm{~d}^{-1}$ in Branchiomma luctuosum; both polychaetes have been proposed with the dual purpose of acting as bioremediators and subsequently serving as food for aquaculture species ( $S$. spallanzanii; Stabili et al. 2013) or as a bioindicator for the surrounding environment, particularly when low levels of pollution make impact assessment extremely complex (Licciano et al. 2007). More recently, filtration estimates performed on S. plicata fed with the microalgae Isochrysis galbana showed values ranging between 1.0 and $1.53 \mathrm{l} \mathrm{h}^{-1} \mathrm{~g} \mathrm{DW}^{-1}$ when chlorophyll concentration varied between 0.3 and $3.1 \mathrm{\mu g} \mathrm{l}^{-1}$ (Montalto et al. 2017). Thus, if we assume an average density of 200 ind. $\mathrm{m}^{-2}$ (which corresponds to the density 
of ascidians present on the panels collected every 3 $\mathrm{mo}$ ) and an average clearance rate equal to $1.01 \mathrm{l} \mathrm{h}^{-1} \mathrm{~g}$ $\mathrm{DW}^{-1}$, the mean filtering capacity in $S$. plicata could be about $4.85 \mathrm{~m}^{3} \mathrm{~g} \mathrm{DW}^{-1} \mathrm{~d}^{-1} \mathrm{~m}^{-2}$; such a species, although it is still poorly used for bioremediative purposes, has been frequently used in the pharmaceutical field. Several examples show how this species can be used for extraction of compound like heparin, with potential uses in treating inflammation (Wang et al. 2002), thrombosis (Myers et al. 2005) and metastasis (Borsig et al. 2001). In addition, aided by a growing interest for functional food ingredients, e.g. nutraceuticals, probiotics, prebiotics and various dietary supplements (Shahidi 2009) that provide health and medical benefits (including the prevention and/or treatment of disease), much of recent research has addressed this important issue. The possibility to extract numerous compounds such as enzymes, proteins, peptides, polysaccharides, polyunsaturated fatty acids, phenolics, pigments and other secondary metabolites from various sources such as prokaryotes, micro- and macroalgae, seaweeds, crustaceans, sponges and other invertebrates as well as various vertebrates, may indeed represent a great potential for biotecnological applications and may be useful to the food industry in a number of applications (Holdt \& Kraan 2011, Freitas et al. 2012, Murray et al. 2013, Boziaris 2014, Dewapriya \& Kim 2014).

In summary, our study supports the novel idea that in suboptimal aquatic conditions such as those occurring in sheltered sites (e.g. hypoxya and/or organic enrichment), important ecosystem services may be supported by fouling communities. In fact, while species that are commonly co-cultivated within aquaculture farms may exhibit signs of disturbance, potentially affecting the whole food web, fouling assemblages in particular cases, such as enclosed locations, may contribute to reduce the environmental impact and at the same time serve as inputs for their re-use in different disciplines. Despite the effect of fouling communities being commonly seen as being negative, there are several studies highlighting the important role of filtration exerted by foulers (e.g. Hughes et al. 2005) as well as how their presence in aquaculture facilities would benefit productions lead to economic savings (Lacoste \& Gaertner-Mazouni 2015) and support the the sustainability of aquaculture in a changing climate (Sarà et al. 2018).

Acknowledgements. PROJECT INNOVAQUA funded by the PON 'Research \& Competitiveness 2007-2013', PON02_ 000451_3362185/1 and the flag-ship project RITMARE (The Italian Research for the Sea-coordinated by the Italian
National Research Council within the National Research Program 2011-2015) who supported this research. We thank Dr. Erika M. D. Porporato for helping in identifying crustacean species and Dr. Antonio Giacoletti, Dr. Marco Martinez, Matteo Mercurio, Alessi Marrone, Rosario Capaci and Carmen Chimera for their support in sampling, sorting and taxonomic identification activities.

\section{LITERATURE CITED}

Anderson MJ (2001) A new method for non-parametric multivariate analysis of variance. Austral Ecol 26:32-46

Ape F, Manini E, Quero GM, Luna GM and others (2019) Biostimulation of in situ microbial degradation processes in organically-enriched sediments mitigates the impact of aquaculture. Chemosphere 226:715-725

Borsig L, Wong R, Feramisco J, Nadeau DR, Varki NM, Varki A (2001) Heparin and cancer revisited: mechanistic connections involving platelets, P-selectin, carcinoma mucins, and tumor metastasis. Proc Natl Acad Sci USA 98:3352-3357

* Boziaris IS (2014) Food ingredients from the marine environment. Marine biotechnology meets food science and technology. Front Mar Sci 1:66

* Bracken MES, Menge BA, Foley MM, Sorte CJB, Lubchenco J, Schiel DR (2012) Mussel selectivity for high-quality food drives carbon inputs into open-coast intertidal ecosystems. Mar Ecol Prog Ser 459:53-62

Bravo FT, Montañes AS (2001) Aquaculture and environment from the perspective of a Spanish fish farmer. Cah Options Méditerr 55:101-109

Chase A (2015) Effects of substrate material on marine fouling community composition and ascidian larval settlement. Master's Theses and Capstones 1041, University of New Hampshire, Durham, NH

Chopin T (2010) Integrated multi-trophic aquaculture. In: Advancing the Aquaculture Agenda: workshop proceedings. OECD, Paris, p 195-217

* Davis AR (1991) Alkaloids and ascidian chemical defense: evidence for the ecological role of natural products from Eudistoma olivaceum. Mar Biol 111:375-379

Dean TA, Hurd LE (1980) Development in an estuarine fouling community: the influence of early colonist on later arrivals. Oecologia 46:295-301

*Dewapriya P, Kim SK (2014) Marine microorganisms: an emerging avenue in modern nutraceuticals and functional foods. Food Res Int 56:115-125

* Duarte CM (2007) Marine ecology warms up to theory. Trends Ecol Evol 22:331-333

* Ezgeta-Balić D, Rinaldi A, Peharda M, Prusina I, Montalto V, Niceta N, Sarà G (2011) An energy budget of the subtidal bivalve, Modiolus barbatus (Mollusca) at different temperatures. Mar Environ Res 71:79-85

Fernandez-Gonzalez V, Toledo-Guedes K, Valero-Rodriguez JM, Agraso MM, Sanchez-Jerez P (2018) Harvesting amphipods applying the integrated multitrophic aquaculture (IMTA) concept in off-shore areas. Aquaculture 489: 62-69

Fitridge I, Dempster T, Guenther J, de Nys R (2012) The impact and control of biofouling in marine aquaculture: a review. Biofouling 28:649-669

Floerl O, Sunde LM, Bloecher N (2016) Potential environmental risks associated with biofouling management in salmon aquaculture. Aquacult Environ Interact 8: $407-417$ 
Freitas AC, Rodrigues D, Rocha-Santos TAP, Gomes AMP, Duarte AC (2012) Marine biotechnology advances towards applications in new functional foods. Biotechnol Adv 30: 1506-1515

Gentry RR, Lester SE, Kappel CV, White C, Bell TW, Stevens J, Gaines SD (2017) Offshore aquaculture: Spatial planning principles for sustainable development. Ecol Evol 7: 733-743

* Giomi F, Pörtner HO (2013) A role for haemolymph oxygen capacity in heat tolerance of eurythermal crabs. Front Physiol 4:110

* Giomi F, Mandaglio C, Ganmanee M, Han GD, Dong YV, Williams GA, Sarà G (2016) The importance of thermal history: costs and benefits of heat exposure in a tropical, rocky shore oyster. J Exp Biol 219:686-694

Hamed I, Özogul F, Özogul Y, Regenstein JM (2015) Marine bioactive compounds and their health benefits: a review. Compr Rev Food Sci Food Saf 14:446-465

Holdt SL, Kraan S (2011) Bioactive compounds in seaweed: functional food applications and legislation. J Appl Phycol 23:543-597

Hughes DJ, Cook EJ, Sayer MDJ (2005) Biofiltration and biofouling on artificial structures in europe: the potential for mitigating organic impacts. Oceanogr Mar Biol Annu Rev 43:123-172

Khalaman VV (2001) Succession of fouling communities on an artificial substrate of a mussel culture in the White Sea. Russ J Mar Biol 27:345-352

Lacoste E, Gaertner-Mazouni N (2015) Biofouling impact on production and ecosystem functioning: a review for bivalve aquaculture. Rev Aquacult 7:187-196

Lane A, Willemsen PR (2004) Collaborative effort looks into biofouling. Fish Farming Int 44:34-35

KLezzi M, Del Pasqua M, Pierri C, Giangrande A (2018) Seasonal non-indigenous species succession in a marine macrofouling invertebrate community. Biol Invasions 20:937-961

K Licciano M, Stabili L, Giangrande A (2005) Clearance rates of Sabella spallanzanii and Branchiomma luctuosum (Annelida: Polychaeta) on a pure culture of Vibrio alginolyticus. Water Res 39:4375-4384

Licciano M, Stabili L, Giangrande A, Cavallo RA (2007) Bacterial accumulation by Branchiomma luctuosum (Annelida: Polychaeta): a tool for biomonitoring marine systems and restoring polluted waters. Mar Environ Res 63:291-302

*Manganaro A, Pulicanò G, Reale A, Sanfilippo M, Sarà G (2009) Filtration pressure by bivalves affects the trophic conditions in Mediterranean shallow ecosystems. Chem Ecol 25:467-478

Mangano MC, Ape F, Mirto S (2019) The role of two nonindigenous serpulid tube worms in shaping artificial hard substrata communities: case study of a fish farm in the central Mediterranean Sea. Aquacult Environ Interact 11:41-51

Mazouni N, Gaertner JC, Deslous-Paoli JM (2001) Composition of biofouling communities on suspended oyster cultures: an in situ study of their interactions with the water column. Mar Ecol Prog Ser 214:93-102

Menon NR, Nair NB (1971) Ecology of fouling bryozoans in Cochin waters. Mar Biol 8:280-307

* Montalto V, Bagarella R, Rinaldi A, Sarà G, Mirto S (2017) Thermal adaptation and physiological responses to environmental stress in tunicates. Aquat Biol 26:179-184

Murray PM, Moane S, Collins C, Beletskaya T and others (2013) Sustainable production of biologically active molecules of marine based origin. New Biotechnol 30:839-850
Myers DD Jr, Rectenwald JE, Bedard PW, Kaila N and others (2005) Decreased venous thrombosis with an oral inhibitor of P selectin. J Vasc Surg 42:329-336

* Neofitou N, Vafidis D, Klaoudatos S (2010) Spatial and temporal effects of fish farming on benthic community structure in a semi-enclosed gulf of the Eastern Mediterranean. Aquacult Environ Interact 1:95-105

Newell RIE (2004) Ecosystem influences of natural and cultivated populations of suspension-feeding bivalve molluscs: a review. J Shellfish Res 23:51-61

Pascoe PL, Parry H, Hawkins AJS (2007) Dynamic filter-feeding responses in fouling organisms. Aquat Biol 1:177-185

*Paul VJ, Puglisi MP (2004) Chemical mediation of interactions among marine organisms. Nat Prod Rep 21:189-209

Pierri C (2007) Variabilità ed evoluzione del macrofouling nel Mar Piccolo di Taranto: ruolo funzionale del polichete Sabella spallanzanii (Gmelin). PhD thesis, University of Salento, Lecce

Price C, Black KD, Hargrave BT, Morris JA Jr (2015) Marine cage culture and the environment: effects on water quality and primary production. Aquacult Environ Interact 6: $151-174$

* Rivero NK, Dafforn K, Coleman MA, Johnston EL (2013) Environmental and ecological changes associated with a marina. Biofouling 29:803-815

* Sarà G, Mazzola A (2004) The carrying capacity for Mediterranean bivalve suspension feeders: evidence from analysis of food availability and hydrodynamics and their integration into a local model. Ecol Modell 179:281-296

Sarà G, Romano C, Caruso M, Mazzola A (2000) The new Lessepsian entry Brachidontes pharaonis (Fischer P., 1870) (Bivalvia, Mytilidae) in the western Mediterranean: a physiological analysis under varying natural conditions. J Shellfish Res 19:967-977

* Sarà G, Lo Martire M, Buffa G, Mannino AM, Badalamenti F (2007) The fouling community as an indicator of fish farming impact in Mediterranean. Aquacult Res 38:66-75

* Sarà G, Romano C, Widdows J, Staff FJ (2008) Effect of salinity and temperature on feeding physiology and scope for growth of an invasive species (Brachidontes pharaonis MOLLUSCA: BIVALVIA) within the Mediterranean sea. J Exp Mar Biol Ecol 363:130-136

* Sarà G, Zenone A, Tomasello A (2009) Growth of Mytilus galloprovincialis (Mollusca, Bivalvia) close to fish farms: a case of integrated multi-trophic aquaculture within the Tyrrhenian Sea. Hydrobiologia 636:129-136

* Sarà G, Palmeri V, Montalto V, Rinaldi A, Widdows J (2013) Parameterisation of bivalve functional traits for mechanistic eco-physiological dynamic energy budget (DEB) models. Mar Ecol Prog Ser 480:99-117

Karà G, Rinaldi A, Montalto V (2014) Thinking beyond organism energy use: a trait based bioenergetic mechanistic approach for predictions of life history traits in marine organisms. PSZNI: Mar Ecol 35:506-515

* Sarà G, Gouhier TC, Brigolin D, Porporato EMD and others (2018) Predicting shifting sustainability trade-offs in marine finfish aquaculture under climate change. Glob Change Biol 24:3654-3665

Sebens K, Sarà G, Nishizaki M (2017) Energetics, particle capture, and growth dynamics of benthic suspension feeders. In: Rossi S, Bramanti L, Gori A, Orejas C (eds) Marine animal forests. Springer, Cham

Shahidi F (2009) Nutraceuticals and functional foods: whole versus processed foods. Trends Food Sci Technol 20: 376-387 
Sokolova IM, Frederich M, Bagwe R, Lannig G, Sukhotin AA (2012) Energy homeostasis as an integrative tool for assessing limits of environmental stress tolerance in aquatic invertebrates. Mar Environ Res 79:1-15

Stabili L, Sicuro B, Daprà F, Gai F and others (2013) The biochemistry of Sabella spallanzanii (Annelida: Polychaeta): a potential resource for the fish feed industry. J World Aquacult Soc 44:384-395

Svendsen MBS, Bushnell BG, Steffensen JF (2016) Design and setup of intermittent-flow respirometry system for aquatic organisms. J Fish Biol 88:26-50

Tang B, Riisgård HU (2018) Relationship between oxygen concentration, respiration and filtration rate in blue mussel Mytilus edulis. J Oceanol Limnol 36:395-404

Terlizzi A, Faimali M (2010) Fouling on artificial substrata. In: Dürr S, Thomason JC (eds) Biofouling. Blackwell Publishing, Chichester, p 170-184

Troell M, Halling C, Neori A, Chopin T, Buschmann AH, Kautsky N, Yarish C (2003) Integrated mariculture: asking the right questions. Aquaculture 226:69-90

Editorial responsibility: Pablo Sánchez Jerez, Alicante, Spain
Troell M, Joyce A, Chopin T (2009) Ecological engineering in aquaculture-potential for integrated multi-trophic aquaculture (IMTA) in marine offshore systems. Aquaculture 297:1-9

Tyrrell MC, Byers JE (2007) Do artificial substrates favor non indigenous fouling species over native species? J Exp Mar Biol Ecol 342:54-60

*Wahl M (2008) Ecological lever and interface ecology: epibiosis modulates the interactions between host and environment. Biofouling 24:427-438

* Wang L, Brown JR, Varki A, Esko JD (2002) Heparin's antiinflammatory effects require glucosamine 6-O-sulfation and are mediated by blockade of L- and P-selectins. J Clin Invest 110:127-136

Wang KL, Wu ZH, Wang Y, Wang CY, Xu Y (2017) Minireview: antifouling natural products from marine microorganisms and their synthetic analogs. Mar Drugs 15:266

Widdows J, Staff F (2006) Biological effects of contaminants: measurement of scope for growth in mussels. ICES Tech Mar Environ Sci, No. 40

Submitted: March 25, 2019; Accepted: October 14, 2019

Proofs received from author(s): December 17, 2019 